\title{
Role of lymphadenectomy for invasive bladder cancer
}

\author{
Faysal A. Yafi, MD; Wassim Kassouf, MD, FRCSC
}

\begin{abstract}
Radical cystectomy with lymph node dissection remains the standard of care in the treatment of muscle-invasive and refractory non-invasive bladder cancer. Over the past decade, the extent of lymphadenectomy has varied to include dissection up to the common iliac vessels and aortic bifurcation proximally (may also extend up to the level of the inferior mesenteric artery), the genitofemoral nerve laterally, the circumflex iliac vein and lymph node of Cloquet distally, and the hypogastric vessels posteriorly (obturator fossa, presciatic nodes bilaterally and the presacral lymph nodes over the sacral promontory). Evidence supports the role of lymphadenectomy as both a therapeutic and prognostic variable in patients with invasive bladder cancer. We review the literature regarding the role and extent of lymphadenectomy, as well as its impact on patient outcomes.
\end{abstract}

Can Urol Assoc J 2009;3(Suppl4):S206-10

\section{Introduction}

In Canada, bladder cancer is the fourth most common cancer in men and the 12th most common in women. It accounts for 6700 new cases and 1780 deaths per year. ${ }^{1}$ Most patients will present with non-muscle-invasive bladder cancer (NMIBC) and $20 \%$ to $30 \%$ will present with muscle-invasive disease. ${ }^{2}$ Radical cystectomy with lymphadenectomy remains the standard of care in the treatment of muscleinvasive and refractory non-invasive bladder cancer. It offers good long-term overall survival (OS) (59\% to 60\%, 5-year OS) and disease-specific survival (DSS) rates (55\% to 65\%, 5-year DSS) as well as excellent 5-year pelvic-control rates of $80 \%$ to $90 \% .^{3-6}$ It also offers precise pathological staging of tumours, allowing for the application of adjuvant chemotherapy when needed. Furthermore, with improvements in surgical technique and postoperative care, complications and perioperative mortality rates are as low as $17 \%$ and $2 \%$, respectively. ${ }^{3-8}$

Even in the era of a more aggressive approach towards high-grade NMIBC, ${ }^{9}$ pathologic specimens from contemporary radical cystectomy series reveal lymph node metastasis in up to $26 \%$ of resected tumours. ${ }^{2}$ There is also a strong correlation between lymph node involvement and the depth of invasion of the primary organ. The rate of lymph node metastasis increases from $5 \%$ in non-muscle-invasive bladder tumours (pT0, pTa, pTis, pT1) to 18\% in superficial muscle-invasive tumours (pT2a), 27\% in deep muscleinvasive tumours and $45 \%$ in extravesical tumours (pT34). ${ }^{3}$ Autopsy specimens provide further support to the elevated incidence of lymph node metastasis with $30 \%$ to $40 \%$ of patients having lymph nodes as the only site of metastasis. ${ }^{2}$ A 5 -year OS up to $31 \%$ can be achieved in higherrisk groups with lymph node metastasis treated with surgical extirpation. ${ }^{3}$ As such, lymphadenectomy is a crucial part of any bladder surgery, since up to one-quarter of clinically organ-confined tumours will have evidence of lymph node metastasis at the time of surgery, making it both an important therapeutic and prognostic tool in the treatment of bladder cancer.

\section{Lymph node mapping}

Initially introduced in the treatment of breast cancer by mastectomy in 1886, ${ }^{10}$ lymph node dissection's (LND) role has broadened over the past decades and is now a mainstay in the approach to patients with muscle-invasive bladder cancer undergoing radical cystectomy. The lymphatic drainage of the bladder is quite extensive and consists of the visceral lymphatic plexus in the bladder muscle wall, the intercalated lymph nodes in the perivesical fat, the pelvic collecting trunks, the regional pelvic nodes (external iliac, hypogastric and sacral) and the lymphatic trunks, which abut on the common iliac nodes. ${ }^{2}$

Though metastasis is found most commonly in the regional pelvic nodes, mapping studies have shown involvement of nodes at or above the aortic bifurcation and at the presacral region in $9 \%$ to $19 \%$ and $5 \%$ to $8 \%$ of cases, respectively. ${ }^{11-13}$ Additionally, in patients with lymph node metastasis within the standard dissection limits, 57\% and 31\% of nodes at the level of the common iliac vessels and above the aortic bifurcation respectively were found to be positive. ${ }^{12}$ Consequentially, a standard LND would have failed to address $74 \%$ of the positive nodes and $7 \%$ of these patients' pathologies would have been falsely reported as negative. ${ }^{12}$ Also of interest is that one-third of patients who had metastasis to the common iliac nodes showed positive nodes in 
the presacral area. ${ }^{13}$ Furthermore, when the bladder cancer was restricted to one side, contralateral nodal metastasis was noted in up to $41 \%$ of cases $^{14}$ and bilateral nodal spread was observed in $39 \%$ of lymph node-positive tumours. ${ }^{15}$ In spite of supporting evidence for an extended bilateral lymph node dissection, controversy remains regarding its surgical limits. An extended LND encompasses the aortic bifurcation and common iliac vessels proximally (may also go up to the level of the inferior mesenteric artery), the genitofemoral nerve laterally, the circumflex iliac vein and lymph node of Cloquet distally, and the hypogastric vessels posteriorly (obturator fossa, presciatic nodes bilaterally and the presacral lymph nodes over the sacral promontory). A standard dissection, however, is usually limited superiorly by the common iliac bifurcation. ${ }^{16}$

\section{Tumour burden}

Tumour burden is defined as the number of positive lymph nodes. As one would predict, the larger the tumour burden, the worse the outcome. Herr and colleagues showed that in patients with positive nodes undergoing radical cystectomy, survival was significantly better when $\leq 4$ positive nodes were present compared with $>4$ positive nodes $(37 \%$ vs. $13 \%) .{ }^{17}$ They also went on to show that when $>11$ nodes were resected, patients showed better survival and less recurrence. These findings were confirmed by another larger study with longer follow-up that showed survival was significantly better in patients with $\leq 8$ metastatic nodes than in those with $>8$ metastatic nodes $(40 \%$ vs. $10 \% 10$-year recurrence-free survival [RFS]). ${ }^{18}$ Improved OS was shown in a study by Steven and Poulsen when 5 or fewer positive nodes were detected $(50 \%$ vs. $13 \%, p<0.002) .{ }^{19}$ Furthermore, the number of involved nodes was associated with improved RFS on univariate analysis $(p=0.04)$ in the study by Kassouf and colleagues but lost statistical significance on multivariate analysis. ${ }^{20}$ The study from the Mansoura group, on the other hand, showed statistical significance on both univariate and multivariate analyses when stratifying positive nodes ( 1 vs. $2-5$ vs. 5 ). ${ }^{21}$ This was also the case in a population-based study from the Surveillance, Epidemiology and End Results (SEER) database (1 vs. 2 vs. 3 vs. $>3$ positive nodes). ${ }^{22}$

\section{Number of lymph nodes resected}

When pelvic recurrence occurs following radical cystectomy, patients usually have very poor prognosis even when offered adjuvant therapy and, as such, it is crucial to have adequate local control. In one study examining 130 patients who underwent limited bilateral pelvic LND and who later developed pelvic recurrence, the median time to recurrence was 7.3 months, with $98.5 \%$ of those patients dying of disease (median survival of 4.9 months). ${ }^{23}$ Skinner was among the first to advocate radical cystectomy with wider resection of perivesical soft tissue and extended LND in an effort to decrease local recurrence of disease and improve cure rates for invasive bladder cancer. A combined effort between the Cleveland Clinic and the University of Bern compared 2 groups of patients who underwent radical cystectomy with either limited LND or extended LND; an extended LND was associated with improved survival in patients with organconfined, non-organ-confined, and/or node-positive tumours. The 5 -year RFS was $77 \%$ for $\mathrm{pT} 2 \mathrm{~N} 0,57 \%$ for $\mathrm{pT} 3 \mathrm{~N} 0$ and $35 \%$ for node-positive tumours in the extended LND group versus $67 \%, 23 \%$ and $7 \%$ respectively in the limited LND group $(p<0.0001) .{ }^{23}$ Another study supported the role of an extended dissection in organ-confined node-negative patients with $90 \% 5$-year RFS compared to only $71 \%$ when a standard LND was performed. ${ }^{24}$ These findings were also confirmed in another cohort of 447 patients with and without nodal involvement undergoing radical cystectomy. ${ }^{25}$

When extended dissection was performed instead of standard dissection, the mean number of nodes collected increased from 14 to 25 and from 8.5 to 36.5 in 2 separate studies. ${ }^{24,26}$ Recent studies have used the number of nodes resected as a surrogate for extent of dissection and surgical quality. When more than 16 nodes were resected the 5 -year RFS jumped from $63 \%$ to $85 \%$ for organconfined tumours and from $25 \%$ to $53 \%$ in patients with at most 1 to 5 positive lymph nodes. A review of the SEER database showed that the factor with the highest impact on survival of patients undergoing radical cystectomy regardless of nodal status and accounting for all traditional prognostic variables was a dissection of at least 10 to 14 nodes. $^{27}$ Furthermore, in the widely quoted Southwest Oncology Group (SWOG) Intergroup trial evaluating the role of neoadjuvant chemotherapy, Herr and colleagues examined surgical factors as surrogates for outcome. ${ }^{28}$ The number of nodes removed $(>10)$ in both node-negative and nodepositive patients was associated with prolonged survival and remained an independent prognostic factor even after adjusting for the use of neoadjuvant chemotherapy, surgical margin status, pT stage and nodal status. Subsequently, Bochner and colleagues tried to establish a minimum number of resected nodes beyond which no effect on survival would be observed. ${ }^{29}$ No such threshold could be determined, since the probability of survival continued to increase as the number of nodes resected increased.

In addition to extent of dissection, node counts are also affected by pathological factors and differences in surgeries, surgeons and institutions. From a pathology perspective, the manner in which specimens are submitted has an effect on yield. This was demonstrated in a prospective study by Bochner and colleagues which showed that submission of nodes in 6 separate lymph node packets versus 
en bloc increases the number of nodes collected by 3 -fold. ${ }^{30}$ Variability of patient's pelvic anatomy is also another factor, with Weingaertner and colleagues demonstrating large interindividual differences with a range of 8 to 56 removed lymph nodes per patient in the pelvic region (mean: 22.7 \pm 10.2 ). ${ }^{31}$ As such, although number of nodes has been increasingly used as a surrogate for surgical quality, other factors may influence this variable; thus, it is rather important to ensure a standardized template of dissection is adopted that extends up to at least the aortic bifurcation. Furthermore, in addition to a therapeutic benefit with an extended LND compared to a limited/standard LND, it is evident that an extended LND offers more accurate staging, increasing detection of micrometastasis and allowing adjuvant chemotherapy to be offered early when tumour burden is lowest.

\section{Morbidity and mortality}

An extended LND, on average, prolongs operative time by 60 minutes and does not appear to be associated with increased morbidity or mortality compared to the standard approach. In large series, early complication and perioperative mortality rates of $28 \%$ and $3 \%$ respectively have been reported. ${ }^{3}$ When comparing patients with positive lymph nodes and those with no lymph node involvement, there was no statistical difference in complications regardless of extravesical involvement (27\% for early complication; $1 \%$ for perioperative mortality). ${ }^{18}$ In a study comparing 2 wellmatched cohorts in terms of comorbidities of 46 patients each, no differences were observed in early complication, perioperative mortality and blood transfusion requirement rates between those who underwent extended LND up to the level of the inferior mesenteric artery and those who underwent standard dissection. ${ }^{32}$ These results were confirmed in a retrospective study comparing extended LND (up to the aortic bifurcation) to a more limited LND; similar mortality rates were observed in the 2 groups with lymphocele formation rates in $1.6 \%$ and $1.5 \%$ respectively. ${ }^{24}$ A prospective, multicentre study comparing similar groups also confirmed these findings, showing higher postoperative lymphatic drainage in the extended LND group without, however, affecting the time to removal of the drains. ${ }^{12}$ As such, extended LND is a safe option in experienced hands and may actually help decrease the rate of positive surgical margins because of wider LND boundaries and also benefits patients secondary to a more complete resection of undetected micrometastases. ${ }^{33}$ It is important to note that extended LND is not recommended in patients who have received high doses of pelvic irradiation (>60Gy), since the procedure may increase the likelihood of vascular complications. ${ }^{34}$

\section{Lymph node density}

To account for both tumour burden and extent of lymphadenectomy as prognostic factors, Herr looked at the ratio of positive nodes to total number of nodes resected. Initially terming it "ratio-based" lymph node staging, Herr showed that in a cohort of 162 patients with nodal metastasis, the 5 -year OS decreased from $64 \%$ when the ratio was $\leq 20 \%$ down to $8 \%$ when it was $>20 \% .{ }^{35}$ This was later termed lymph node density by the University of Southern California group, which similarly showed worsening 10-year RFS from $43 \%$ when the lymph node density was $\leq 20 \%$ to merely $17 \%$ when it was $>20 \% .{ }^{18}$ These findings were further validated by Kassouf and colleagues and showed that lymph node density remains prognostic even in patients who received adjuvant chemotherapy. ${ }^{20} \mathrm{~A}$ pooled analysis of MD Anderson and Memorial Sloan-Kettering Cancer Centers showed that lymph node density is superior to TNM nodal status in predicting disease-specific survival after radical cystectomy for bladder cancer. For lymph node density to be powerful, a minimum number of nodes resected needs to be identified; one study showed that at least 9 nodes need to be removed. ${ }^{36}$ This strategy has shown promise as a staging and prognostic tool and may be useful to better stratify patients when entering them in clinical trials designed to study the role of adjuvant therapy. Most of the data support the incorporation of lymph node density into the staging system (Table 1). The predictive power of lymph node density can potentially be enhanced by accounting for other variables such as the presence of extracapsular extension, volume of micrometastasis and anatomic location of positive nodes.

\section{Conclusion}

Radical cystectomy with bilateral pelvic lymphadenectomy remains the standard of care for muscle-invasive bladder cancer. An extended lymphadenectomy is recommended for patients without contraindications, such as serious comorbidities and prior high-dose pelvic irradiation since it offers survival benefit to patients with both node-positive and node-negative disease without increasing morbidity or perioperative mortality. There continues to be debate as to how high an extended LND should be performed, with evidence pointing towards reaching proximally to the level of the inferior mesenteric artery. Pathologic stage, tumour burden and extent of lymphadenectomy are well established risk factors; however, lymph node density appears to be the most promising prognostic tool for node-positive tumours.

From the Department of Surgery (Urology), McGill University, Montréal, QC

Competing interests: None declared.

This paper has been peer-reviewed. 
Role of lymphadenectomy in bladder cancer

Table 1. Extent of lymphadenectomy studies

\begin{tabular}{|c|c|c|c|c|c|c|c|c|}
\hline Studies & $\begin{array}{c}\text { No. } \\
\text { patients }\end{array}$ & $\begin{array}{l}\text { Extent of } \\
\text { LND }\end{array}$ & $\begin{array}{l}\text { Median } \\
\text { number of nodes } \\
\text { resected }\end{array}$ & $\begin{array}{l}\text { Cut-off number } \\
\text { of nodes } \\
\text { resected }\end{array}$ & Cut-off LND (\%) & 5-year OS & 5-year RFS & 5-year DSS \\
\hline \multirow[t]{2}{*}{ Stein et al. ${ }^{18}$} & 244 & $\begin{array}{l}\text { Above aortic } \\
\text { bifurcation }\end{array}$ & $30(1-96)$ & & $\begin{array}{l}\leq 20 \\
>20\end{array}$ & $\begin{array}{c}43 \% \\
8 \% \\
p<0.001\end{array}$ & $\begin{array}{c}44 \% \\
17 \% \\
p<0.001\end{array}$ & $\mathrm{~N} / \mathrm{A}$ \\
\hline & & & & $\begin{array}{l}\geq 15 \text { nodes } \\
<15 \text { nodes }\end{array}$ & & N/A & $\begin{array}{c}36 \% \\
25 \% \\
p=0.21\end{array}$ & N/A \\
\hline \multirow[t]{2}{*}{ Konety et al. ${ }^{27}$} & 361 & Extended & $\mathrm{N} / \mathrm{A}$ & & $\begin{array}{l}\leq 50 \\
>50\end{array}$ & N/A & N/A & $\begin{array}{c}\mathrm{HR}=1.55 \\
p=0.27\end{array}$ \\
\hline & & & & 10-14 nodes & & N/A & N/A & $\begin{array}{l}\mathrm{HR}=0.38 \\
p<0.0001\end{array}$ \\
\hline \multirow[t]{2}{*}{$\mathrm{Herr}^{35}$} & 162 & Distal common iliac & $13(2-32)$ & & $\begin{array}{l}\leq 20 \\
>20\end{array}$ & N/A & $\mathrm{N} / \mathrm{A}$ & $\begin{array}{c}64 \% \\
8 \% \\
p=0.002\end{array}$ \\
\hline & & & & $\begin{array}{l}\geq 13 \text { nodes } \\
<13 \text { nodes }\end{array}$ & & $\mathrm{N} / \mathrm{A}$ & $\mathrm{N} / \mathrm{A}$ & NSS \\
\hline \multirow[t]{2}{*}{ Kassouf et al. ${ }^{20}$} & 108 & $\begin{array}{l}\text { Below aortic } \\
\text { bifurcation }\end{array}$ & $12(1-58)$ & & $\begin{array}{l}\leq 25 \\
>25\end{array}$ & $\begin{array}{c}37 \% \\
19 \% \\
p=0.02\end{array}$ & $\begin{array}{c}38 \% \\
11 \% \\
p=0.02\end{array}$ & N/A \\
\hline & & & & $\begin{array}{l}>12 \text { nodes } \\
\leq 12 \text { nodes }\end{array}$ & & N/A & NSS & $\mathrm{N} / \mathrm{A}$ \\
\hline \multirow[t]{2}{*}{ Kassouf et al. ${ }^{36}$} & 248 & $\begin{array}{l}\text { Below aortic } \\
\text { bifurcation }\end{array}$ & $12(2-58)$ & & $\begin{array}{l}\leq 20 \\
>20\end{array}$ & N/A & N/A & $\begin{array}{c}55 \% \\
15 \% \\
p<0.001\end{array}$ \\
\hline & & & & $\begin{array}{l}>12 \text { nodes } \\
\leq 12 \text { nodes }\end{array}$ & & N/A & N/A & $\begin{array}{l}\mathrm{HR}=0.41 \\
p<0.01^{*}\end{array}$ \\
\hline \multirow[t]{2}{*}{$\begin{array}{l}\text { Fleischmann } \\
\text { et al. }{ }^{37}\end{array}$} & 101 & Common iliac artery & $22(10-43)$ & & $\begin{array}{l}<20 \\
\geq 20\end{array}$ & $\begin{array}{c}40 \% \\
15 \% \\
p=0.002 *\end{array}$ & $\begin{array}{c}41 \% \\
15 \% \\
p=0.003^{*}\end{array}$ & N/A \\
\hline & & & & $\begin{array}{l}\geq 5 \text { nodes } \\
<5 \text { nodes }\end{array}$ & & $\begin{array}{c}\mathrm{N} / \mathrm{A} \\
p=0.0002^{\dagger}\end{array}$ & $\begin{array}{c}\mathrm{N} / \mathrm{A} \\
p=0.0005^{\dagger}\end{array}$ & N/A \\
\hline \multirow[t]{2}{*}{ Wright et al. ${ }^{22}$} & 1260 & Extended & $9(1-75)$ & & $\begin{array}{l}\leq 12.5 \\
>12.5\end{array}$ & $\begin{array}{l}\mathrm{HR}=1.31 \\
p<0.001\end{array}$ & $\mathrm{~N} / \mathrm{A}$ & $\begin{array}{l}\mathrm{HR}=1.24 \\
p<0.001\end{array}$ \\
\hline & & & & $\begin{array}{l}\geq 10 \text { nodes } \\
<10 \text { nodes }\end{array}$ & & $\begin{array}{l}\mathrm{HR}=0.52 \\
p<0.001\end{array}$ & $\mathrm{~N} / \mathrm{A}$ & $\begin{array}{l}\mathrm{HR}=0.53 \\
p<0.001\end{array}$ \\
\hline \multirow[t]{2}{*}{ Steven et al. ${ }^{19}$} & 64 & $\begin{array}{l}\text { Above aortic } \\
\text { bifurcation }\end{array}$ & $27(11-49)$ & & $\begin{array}{l}\leq 20 \\
>20\end{array}$ & $\begin{array}{c}47 \% \\
25 \% \\
p<0.05\end{array}$ & $\begin{array}{c}40 \% \\
15 \% \\
p<0.01\end{array}$ & N/A \\
\hline & & & & $\mathrm{N} / \mathrm{A}$ & & N/A & N/A & N/A \\
\hline \multirow[t]{2}{*}{$\begin{array}{l}\text { Abdel-Latif } \\
\text { et al. } .^{21}\end{array}$} & 110 & Distal common iliac & $\begin{array}{c}\text { Mean } \\
17.9 \pm 6.7\end{array}$ & & $\begin{array}{l}\leq 20 \\
>20\end{array}$ & N/A & $\begin{array}{c}39 \% \\
16 \% \\
p<0.001^{\dagger}\end{array}$ & N/A \\
\hline & & & & Continuous & & N/A & NSS & N/A \\
\hline \multirow[t]{2}{*}{ Lerner et al. ${ }^{38}$} & 132 & $\begin{array}{l}\text { Above aortic } \\
\text { bifurcation }\end{array}$ & $31(3-96)$ & & $\begin{array}{l}\leq 25 \\
>25\end{array}$ & NSS & NSS & N/A \\
\hline & & & & N/A & & N/A & N/A & N/A \\
\hline \multirow[t]{2}{*}{ Leissner et al. ${ }^{25}$} & 302 & Variable & $14.7(1-46)$ & & $\mathrm{N} / \mathrm{A}$ & N/A & N/A & $\mathrm{N} / \mathrm{A}$ \\
\hline & & & & $\begin{array}{l}\geq 16 \text { nodes } \\
<16 \text { nodes }\end{array}$ & & N/A & $\begin{array}{c}65 \% \\
51 \% \\
p<0.016\end{array}$ & $\begin{array}{c}65 \% \\
51 \% \\
p<0.013\end{array}$ \\
\hline \multirow[t]{2}{*}{ Herr et al. ${ }^{28}$} & 268 & Variable & $10(0-54)$ & & $\mathrm{N} / \mathrm{A}$ & $\mathrm{N} / \mathrm{A}$ & $\mathrm{N} / \mathrm{A}$ & N/A \\
\hline & & & & $\begin{array}{l}\geq 10 \text { nodes } \\
<10 \text { nodes }\end{array}$ & & $\begin{array}{c}61 \% \\
44 \% \\
p=0.0007\end{array}$ & $\begin{array}{c}25 \% \\
6 \% \\
p<0.0001\end{array}$ & N/A \\
\hline \multirow[t]{4}{*}{ Herr et al. ${ }^{17}$} & 322 & Variable & $8(0-44)$ for $\mathrm{pN} 0$ & & $\mathrm{~N} / \mathrm{A}$ & N/A & N/A & N/A \\
\hline & & & & $\begin{array}{l}\geq 8 \text { nodes } \\
<8 \text { nodes }\end{array}$ & & $\begin{array}{c}\text { pN0 } \\
p=0.0000\end{array}$ & N/A & N/A \\
\hline & & & $\begin{array}{l}11(1-25) \\
\text { for } \mathrm{pN}+\end{array}$ & & $\mathrm{N} / \mathrm{A}$ & N/A & N/A & N/A \\
\hline & & & & $\begin{array}{l}\geq 11 \text { nodes } \\
<11 \text { nodes }\end{array}$ & & $\begin{array}{c}\mathrm{pN}+ \\
p=0.004\end{array}$ & N/A & $\mathrm{N} / \mathrm{A}$ \\
\hline \multirow[t]{2}{*}{ Koppie et al. ${ }^{29}$} & 1042 & Variable & $9(0-53)$ & & $\mathrm{N} / \mathrm{A}$ & N/A & N/A & N/A \\
\hline & & & & Continuous & & $\begin{array}{l}\mathrm{HR}=0.97 \\
p<0.0005\end{array}$ & N/A & N/A \\
\hline \multirow[t]{2}{*}{ Poulsen et al. ${ }^{24}$} & 117 & & & & N/A & N/A & & N/A \\
\hline & & $\begin{array}{l}\text { Extended } \\
\text { Limited }\end{array}$ & $\begin{array}{l}25(9-67) \\
14(5-30)\end{array}$ & $\begin{array}{l}\text { Extended } \\
\text { Limited }\end{array}$ & & & $\begin{array}{c}\leq \mathrm{pT} 3 \mathrm{a} \\
85 \% \\
64 \% \\
p<0.02\end{array}$ & N/A \\
\hline \multirow[t]{2}{*}{ Dhar et al. ${ }^{23}$} & $\begin{array}{c}336, \\
\text { Cleveland Clinic; } \\
322, \\
\text { University of Bern }\end{array}$ & $\begin{array}{l}\text { Extended } \\
\text { Limited }\end{array}$ & $\begin{array}{l}22(10-43) \\
12(2-31)\end{array}$ & $\begin{array}{l}\text { Extended } \\
\text { Limited }\end{array}$ & $\mathrm{N} / \mathrm{A}$ & $\begin{array}{c}\mathrm{pN}+ \\
34 \% \\
7 \% \\
p<0.0001\end{array}$ & $\begin{array}{c}\mathrm{pN}+ \\
35 \% \\
7 \% \\
p<0.0001\end{array}$ & $\mathrm{~N} / \mathrm{A}$ \\
\hline & & & & $\begin{array}{l}\text { Extended } \\
\text { Limited }\end{array}$ & $\mathrm{N} / \mathrm{A}$ & $\begin{array}{c}\text { pT3N0 } \\
46 \% \\
26 \% \\
p=0.002^{1}\end{array}$ & $\begin{array}{c}\text { pT3N0 } \\
57 \% \\
23 \% \\
p<0.0001\end{array}$ & N/A \\
\hline
\end{tabular}

DSS = disease-specific survival; LND = lymph node density; N/A = not available; NSS = not statistically significant; OS = overall survival; RFS = recurrence-free survival; HR = hazard ratio ${ }^{*}=$ Univariate analysis, not statistically significant on multivariate analysis; $\dagger=$ mean 3 -year survival. 


\section{References}

1. Marrett LD, De P, Dryer D; for the Steering Committee of Canadian Cancer Statistics 2008. Cancer in Canada in 2008. CMAJ 2008;179:1163-70.

2. Stein JP, Quek ML, Skinner DG. Lymphadenectomy for invasive bladder cancer: I. Historical perspective and contemporary rationale. BJU Int 2006;97:227-31.

3. Stein JP, Lieskovsky $\mathrm{G}$, Cote R, et al. Radical cystectomy in the treatment of invasive bladder cancer: long-term results in 1,054 patients. J Clin Oncol 2001;19:666-75.

4. Madersbacher $S$, Hochreiter W, Burkhard F, et al. radical cystectomy for bladder cancer today- a homogeneous series without neoadjuvant therapy. J Clin Oncol 2003;4:690-6.

5. Ghoneim MA, Abdel-Latif $M$, El-Mekresh $M$, et al. Radical cystectomy for carcinoma of the bladder: 2,720 consecutive cases 5 years later. J Urol 2008;180:121-7.

6. Shariat SF, Karakiewicz PI, Palapattu GS, et al. Outcomes of radical cystectomy for transitional cell carcinoma of the bladder: a contemporary series from the Bladder Cancer Research Consortium. J Urol 2006;176:2414-22.

7. World Health Organization (WHO) Consensus Conference on Bladder Cancer; Hautmann R, Abol-Enein H, Hafez K et al. Urinary diversion. Urology 2007;69:17-49.

8. Kessler T. Attempted nerve-sparing surgery and age have a significant effect on urinary continence and erectile function after radical cystoprostatectomy and ileal orthotopic substitution. J Urol 2004;172:1323-7.

9. Stein JP. Indications for early cystectomy. Urology 2003;62:591-5.

10. Halstead WS. The treatment of wounds. Johns Hopkins Hosp Rep 1891;2:279.

11. Smith JA Jr, Whitmore WF Jr. Regional lymph node metastasis from bladder cancer. J Urol 1981;126:591-3

12. Leissner J, Ghoneim MA, Abol-Enein $\mathrm{H}$, et al. Extended radical lymphadenectomy in patients with urothelial bladder cancer: results of a prospective multicenter study. J Urol 2004;171:139-44.

13. Vazina A, Dugi D, Shariat SF, et al. Stage specific lymph node metastasis mapping in radical cystectomy specimens. J Urol 2004;171:1830-4.

14. Mills RD, Turner WH, Fleischmann A, et al. Pelvic lymph node metastases from bladder cancer. Outcome in 83 patients after radical cystectomy and pelvic lymphadenectomy. J Urol 2001;166:19-23.

15. Abol-Enein $\mathrm{H}$, El-Baz M, Abd El-Hameed MA, et al. Lymph node involvement in patients with bladder cancer treated with radical cystectomy: a patho-anatomical study-a single center experience. J Urol 2004;172:1818-21.

16. Stein JP, Quek ML, Skinner DG. Lymphadenectomy for invasive bladder cancer. II. Technical aspects and prognostic factors. BJU Int 2006;97:232-7.

17. Herr HW, Bochner BH, Dalbagni $G$, et al. Impact of the number of lymph nodes retrieved on outcome in patients with muscle invasive bladder cancer. J Urol 2002;167:1295-8.

18. Stein JP, Cai J, Groshen $S$, et al. Risk factors for patients with pelvic lymph node metastasis following radical cystectomy with en bloc pelvic lymphadenectomy: concept of lymph node density. I Urol 2003;170:35-41.

19. Steven K, Poulsen AL. Radical cystectomy and extended pelvic lymphadenectomy: survival of patients with lymph node metastasis above the bifurcation of the common iliac vessels treated with surgery alone. J Urol 2007;178:1218-23.

20. Kassouf W, Leibovici D, Munsell MF, et al. Evaluation of the relevance of lymph node density in a contemporary series of patients undergoing radical cystectomy. J Urol 2006;176:53-7.
21. Abdel-Latif M, Abol-Enein H, El-Baz M, et al. Nodal involvement in bladder cancer cases treated with radical cystectomy: incidence and prognosis. J Urol 2004;172:85-9.

22. Wright JL, Lin DW, Porter MP. The association between extent of lymphadenectomy and survival among patients with lymph node metastasis undergoing radical cystectomy. Cancer 2008;112:2401-8.

23. Dhar NB, Klein EA, Reuther AM, et al. Outcome after radical cystectomy with limited or extended pelvic lymph node dissection. J Urol 2008;179:873-8.

24. Poulsen AL, Horn T, Steven K. Radical cystectomy: extending the limits of pelvic lymph node dissection improves survival for patients with bladder cancer confined to the bladder wall. J Urol 1998;160:2015-9.

25. Leissner J, Hohenfellner R, Thuroff JW, et al. Lymphadenectomy in patients with transitional cell carcinoma of the urinary bladder; significance for staging and prognosis. BJU Int 2000;85:817-23.

26. Bochner BH, Herr HW, Reuter VE. Impact of separate versus en bloc pelvic lymph node dissection on the number of lymph nodes retrieved in cystectomy specimens. J Urol 2001;166:2295-6.

27. Konety BR, Joslyn $S A, O^{\prime}$ Donnell MA. Extent of pelvic lymphadenectomy and its impact on outcome in patients diagnosed with bladder cancer: analysis of data from the Surveillance, Epidemiology and End Results Program data base. J Urol 2003;169:946-50.

28. Herr HW, Faulkner JR, Grossman HB, et al. Surgical factors influence bladder cancer outcomes: a cooperative group report. J Clin Oncol 2004;22:2781-9.

29. Koppie TM, Vickers AJ, Vora K, et al. Standardization of pelvic lymphadenectomy performed at radical cystectomy: can we establish a minimum number of lymph nodes that should be removed? Cancer 2006;107:2368-74.

30. Bochner BH, Cho D, Herr HW, et al. Prospectively packaged lymph node dissections with radical cystectomy: evaluation of node count variability and node mapping. J Urol 2004;172:1286-90.

31. Weingartner K, Ramaswamy A, Bittinger A, et al. Anatomic basis of pelvic lymphadenectomy in prostate cancer: results of an autopsy study and implications for the clinic. J Urol 1996;156:1969-71.

32. Brossner C, Pycha A, Toth A, et al. Does extended lymphadenectomy increase the morbidity of radical cystectomy? BJU Int 2004; $93: 64-6$.

33. Sanderson KM, Skinner D, Stein JP. The prognostic and staging value of lymph node dissection in the treatment of invasive bladder cancer. Nat Clin Pract Urol 2006;3:485-94.

34. Crawford ED, Skinner DG. Salvage cystectomy after irradiation failure. J Urol 1980;123:32-4.

35. Herr HW. Superiority of ratio based lymph node staging for bladder cancer. J Urol 2003;169:943-5.

36. Kassouf W, Aqarwal PK, Herr HW, et al. Lymph node density is superior to TNM nodal status in predicting disease-specific survival after radical cystectomy for bladder cancer: analysis of pooled data from MDACC and MSKCC. J Clin Oncol 2008;26:121-6.

37. Fleischmann A, Thalmann GN, Markwalder R, et al. Extracapsular extension of pelvic lymph node metastases from urothelial carcinoma of the bladder is an independent prognostic factor. I Clin Oncol 2005;23:2358-65.

38. Lerner SP, Skinner DG, Lieskovsky G, et al. The rationale for en bloc pelvic lymph node dissection for bladder cancer patients with nodal metastases: long-term results. J Urol 1993;149:758-64.

Correspondence: Dr. Wassim Kassouf, Division of Urology, McGill University Health Centre, 1650 Cedar Avenue, Rm L8-315, Montréal, QC H3G 1A4; fax: 514-934-8297; wassim.kassou@@muhc.mcgill.ca 